\title{
THE STUDENT VOICE AS CONTRIBUTOR TO QUALITY EDUCATION THROUGH INSTITUTIONAL DESIGN
}

\section{F. Strydom*}

Centre for Teaching and Learning

e-mail: strydomif@ufs.ac.za / https://orcid.org/0000-0002-4338-8127

\section{S. Loots*}

Centre for Teaching and Learning

e-mail: lootss@ufs.ac.za / https://orcid.org/0000-0002-8268-8851

*University of the Free State

Bloemfontein, South Africa

\section{ABSTRACT}

The inclusion of students' voices in different aspects of quality has evolved over the years. Consequently, students take on different roles - ranging from providing feedback on their educational experiences, to actively participating or even leading change initiatives. In making claims for different ways of conceptualising or including students' voices, the literature often criticises some forms of engagement with student voices in favour of another. This article is based on the premise that the complexity of quality outcomes in higher education needs to be complemented by a variety of inputs from students. By drawing from examples of two high-impact practices from the University of the Free State, the article further argues for using different forms of student voices to inform how we design institutional support structures to ultimately enhance the quality of students' educational experiences. At its core, this cyclical interaction between students' voices and institutional design revolves around evidence - thereby contributing to the quality of educational outcomes, and ultimately students' success.

Keywords: student voice, quality, institutional design, student success

\section{INTRODUCTION}

In keeping with international trends, the conceptualisation of quality in the South African higher education sector has evolved over the years towards a strong focus on how we are preparing students to be productive contributors to the economy and society. Students' contribution to the idea of quality education mapped in relation to the processes and outcomes of higher education has also evolved over the years. Students' voices in higher education are included in a variety of ways, ranging from feedback on learning experiences to involving students in curriculum design, and including student representation in decision-making processes. These different activities of involvement also imply different roles students adopt (Seale 2016). Combining 
these two concepts - quality as outcome of higher education and the contribution of students' voices, this article reflects on the current state of quality outcomes in the sector; how student voices are represented; and how institutions could align the two concepts in designing interventions to enhance both.

\title{
QUALITY AS EDUCATIONAL OUTCOME: WHAT ARE WE WORKING TOWARDS?
}

In the 1990s, Barnett (1994) commented that the discourse on quality had shifted from focusing on quality assurance (assessing the current state of quality) to quality enhancement (what quality could/should look like from different perspectives). This idea of quality has evolved since. A recent publication by Hazelkorn, Coates and McCormick (2018) positions quality, performance and accountability as representing three of the most significant challenges affecting modern higher education. Regarding quality specifically, Hazelkorn and her colleagues provide an extensive conceptualisation of modern-day quality in higher education sectors and institutions:

\begin{abstract}
"Quality refers to teaching and learning, although it also refers to research, engagement and institutional leadership. Increasingly, consideration of quality extends beyond internal matters and reflects the capacity and capability of higher education to meet a variety of societal needs and demands. It is often used in association or conterminously with 'excellence' as if to assert or emphasise the objective of quality. Thus, quality considers such matters as: the production of new knowledge and capacity for innovation; student learning outcomes; the educational or learning gain in both declarative knowledge and more diffuse 'soft skills'; student performance, retention, graduation and employability; support for student success; the production of suitably trained and demographically representative graduates at different educational levels; the breadth and depth of the curriculum and its responsiveness to contemporary needs; pedagogical methods, training and academic support and development; and links to societal practice and working life, including graduates' preparedness as citizens and lifelong learners. Other aspects include how well higher education institutions or the system as a whole is governed, managed and assured, student learning pathways and progression through the system, and equity of access, participation and opportunity." (Hazelkorn et al. 2018, 6).
\end{abstract}

The shift in focus from quality assurance to quality enhancement in South Africa was a gradual process. In the turmoil of transition to a democratic state, initial focus in the 1990s was placed on restructuring the sector and formulating policies to guide its development in a new era. A sector-wide quality assurance focus between 2004 and 2011 culminated in institutional audits, after which the Council on Higher Education (CHE) broadened the focus of quality to the Quality Enhancement Project (QEP). The QEP aligns with conceptualisations of quality enhancement, as well as the sectoral move from widening participation to a stronger focus on 
the amalgamation of access and success. It aimed to enhance all aspects of teaching and learning in order to improve student success - the latter is defined as "enhanced student learning with a view to increasing the number of graduates with attributes that are personally, professionally and socially valuable" (CHE 2014, ii). From a student's perspective, contributions from over 250 students conceptualise a quality education in South Africa as developing relevant skills, enabling graduates to be economically productive, contributing to personal and the country's transformation, having well-qualified lecturers, and excellence in teaching and learning (Fomunyam 2016). All three conceptualisations of quality education have a strong focus on the outcomes of higher education for students.

\section{THE CURRENT STATE OF QUALITY AS AN OUTCOME OF HIGHER EDUCATION IN SOUTH AFRICA}

In 1990 the enrolment figure for public universities was 378707 (Ndebele 2017). This figure has increased threefold to over one million students enrolled in public universities in 2017 (Department of Higher Education and Training [DHET] 2019a). Longitudinal data from the DHET (2019b) shows significant improvements in reducing students' first year attrition rates. This includes, for example, a 10 per cent reduction in first-year dropouts in contact mode institutions between 2000 and 2016. Similarly, the same group shows a 15 per cent increase in graduates after six years in the system. As much as these increases in access and throughput should be celebrated, the sector still faces several challenges. These include system bottlenecks, persistent inequities in students' success, skills mismatches between the sector and labour market, and a general lack of evidence to prove students' capabilities. Longitudinal analyses of CHE data between 2010 and 2017 show that throughput rates in the minimum time allocated for three-year degrees have not breached 30 per cent. ${ }^{1}$ Regarding inequities, as with access, there is still a discrepancy between race and gender regarding graduation rates. For example, 56 per cent of African students complete their three-year degrees within six years, while 72 per cent of white students do so in the same timeframe. There is also a difference of approximately 10 per cent between males and females relevant to both racial groups, with all females graduating faster than males (DHET 2019b).

Regarding skills mismatches, while South Africa has an oversupply of low-skilled workers, the country is in need of producing higher-skilled workers, particularly in current and future fields of education, healthcare, information and communication technologies, agriculture, and fields that would contribute to a green economy (Organisation for Economic Co-operation and Development [OECD] 2017; Reddy et al. 2017). The OECD (2017) also reports that almost a third of workers in South Africa are underqualified, while around a quarter 
are overqualified for the positions they are employed in. A third are also employed in fields outside their expertise. We do, however, know that graduates are more likely to be employed than any other groups with lower or different qualifications. For example, while almost a third of graduates between the ages of 15 and 24 are unemployed, this figure decreases to 13 per cent unemployment for those aged 25 to 34 , and even further to 4 per cent among those older than 35 years of age. In contrast, 55 per cent of those with a matric qualification between the ages of 15 and 24 are unemployed, and although the percentage also declines with age, there is still approximately a 20 per cent difference in unemployment figures between graduates and matriculants over time (Statistics South Africa 2019). Investing in higher education in South Africa yields big returns. In fact, Cloete (2016) shares analyses of different studies stressing the significant impact higher education is making in Sub-Saharan Africa's development, including overwhelming evidence of the return on investment for South African graduates specifically.

Beyond these broad sectoral statistics, the inner workings of institutions and how they contribute to quality outcomes are less overt. As part of the QEP, public institutions were asked to report on progress in four focus areas: enhancing academics as teachers; enhancing student support and development; enhancing the learning environment; and enhancing course and programme enrolment management (CHE 2015). The analyses found that although a variety of activities are taking place on campuses to enhance university teaching, a uniformed approach to cater for the diversity of the sector is found to be lacking. This finding also contributed to the formulation of the National Framework for Enhancing Academics as University Teachers (DHET 2018), which has been accepted in principle, but has not since been given much more public attention. In terms of supporting students, the majority of institutions have implemented some form of peer support structures (e.g. tutorials, supplemental instruction, mentoring, etc.), as well as academic literacy support. Some have ventured into data analytics to identify, nudge and track students who might need additional support. However, many of these interventions lack an evidence-base of "what works" to help students succeed. That said, academic literature on interventions helping students succeed has increased significantly in the past few years, particularly regarding the importance of identifying and addressing students' academic and non-academic support needs (e.g. Knoesen and Naude 2017; Manik 2015; Mayet 2016; McGhie and du Preez 2015); and support structures such as peer learning programmes (i.e. tutorials, mentorship, supplemental instruction) (Dos Reis and Yu 2018; Layton 2015; Makala 2017; Masehela and Mabika 2017; McKay 2016). The vast majority of these studies, however, are programme or course-based and do not report on institutional-level interventions.

The broad analyses of access, throughput, and success, as well as some of the current efforts put in place to mitigate these factors give us a glimpse of quality. However, they do not 
tell us much about the skills and capabilities or attributes that students develop during their time at university, nor do they tell us much about the students' involvement in these processes.

\section{POSITIONING THE STUDENT VOICE IN QUALITY AS AN EDUCATIONAL OUTCOME}

Students' participation in higher education quality measures has evolved from providing feedback to guide internal practices to governments introducing policy documents to facilitate students' inclusion in different aspects of institutional governance. In the United Kingdom and Australia, for example, students' feedback on their educational experiences is made available to the public in order to increase transparency and accountability (Shah, Cheng and Fitzgerald 2017).

For the most part, students' involvement in institutional processes takes place through a number of established routes and roles that might include student representatives, unions, associations, forums, survey respondents, and co-researchers (Hall 2017). However, it is not always clear what the impact of students' involvement in the broader scheme of things is as there is not a lot of evidence to show what the impact of students' contributions is on a broader scale (i.e. beyond how a specific course curriculum changed, etc.) This might be because students' contributions are often part of processes informing practice, which might not be shared beyond the intended purpose of participation (Seale 2016).

\section{Emphasis on student voice}

Students evaluating their

HE experience (feedback,

views and opinions; building

an evidence-base to inform

institutional decisions
Students participating in decision-making processes

(institutional decisions to influence change; collaborative action)
University as driver

Students as partners and co-creators (collaborative partners in curriculum review; professional development)
Student as driver

Students as agents for

change (collaborative partners

in pedagogic knowledge

acquisition; promoting decisions

for action)

Emphasis on student action

Figure 1: A model for students as change agents. Adapted from Dunne and Zanstra (2011) 
A useful model to conceptualise the inclusion of student voice in higher education is taken from Dunne and Zanstra (2011), who developed a model for students as change agents (Figure 1). The authors argue that the efforts of institutions to engage with and include students were missing an element of students actually bringing about change. In their proposed model, Dunne and Zanstra differentiate between four forms of student involvement in institutional policy and practice, all placed within a spectrum of voice vs. action on the vertical axis, and university vs. student as drivers of voice/action on the horizontal axis.

\section{Students as evaluators}

Arguably, the most familiar quadrant in Zunne and Dunstra's model is the recognition of students' voices through their evaluations of educational experiences. This might include processes through which the institution and external bodies listen to the student voice in order to drive change. Parallel to a stronger association of student learning and development with institutional quality, a focus on student satisfaction and student engagement research in educationally purposeful activities increased. The surveys used to measure students' experiences and engagement have become a central tenet of measuring quality in higher education and holding institutions accountable. In addition, these survey results are used by institutions to promote their strengths and market themselves to potential students. Besides the National Survey of Student Engagement (NSSE) in the United States that publish how participating universities are using the data to improve their institutions, ${ }^{2}$ how higher education institutions effectively use student feedback to improve learning remains an area less explored (Klemenčič and Chirikov 2015; Shah et al. 2017).

The use of students' voices as evaluators of educational experiences has prompted some critique. For example, Dunne and Zunstra (2011) argue that there is a difference between institutions that listen to students' voices and act accordingly, versus institutions that give students the opportunity to generate their own ideas, solutions to problems, and bring about changes. Merely listening to students' voices, they claim, supports the perspective of the student as a consumer. In a similar vein, Canning $(2017,519)$ argues that the student voice, as it is positioned as being important to quality enhancement, relates to a "consumer panel" conception of student voice that places the university firmly as a business and the student as the customer. A further complication in such a model is that students' complaints, as consumers, are often expressed in public, particularly in online spaces. 


\section{Students as participants}

Positioning students as participants in decision-making processes shows institutional commitment to greater student involvement in changes to teaching, learning and institutional development. It often manifests through students' active involvement in committees, departments, or other governance structures (Dunne and Zanstra 2011). In South Africa, the Higher Education Act includes students as participants in all governance structures, up to the highest Councils (Republic of South Africa 1997). Including students as participants in governance structures also provides opportunities to contribute to quality in the form of transformation of the South African higher education system, which, as Waghid (2019) argues, takes place through democratic human engagement.

\section{Students as partners}

Including students as partners emphasises active student engagement as co-creators and experts. It includes student engagement in institutional development, teaching and learning spaces, as well as through research. Dunne and Zanstra (2011) argue that student-led research on the learning and teaching environment fosters valuable employability skills and makes an important contribution to engagement within their institution.

Involving students as partners in reviewing pedagogical practices has also been promoted. For example, Brooman, Darwent and Pimor (2015) find a causal link between student involvement in curriculum design and enhanced learning. In South Africa, Nel (2017) reflects on how her collaborative relationship with students has contributed to creating meaningful learning experiences for students, as well as developing her own teaching philosophy and styles. Mudehwe-Gonhovi, Galloway and Moyo (2018) report on the liberation students experienced when contributing to knowledge creation through participating in dialogic pedagogy.

\section{Students as agents of change}

While the idea of students as partners places students as co-creators of institutional strategy, positioning students as change agents implies that they need to be actively engaged in the processes of change, and often taking up leadership roles (Seale 2016). Arguably, the most common example of students as change agents is through activism. In recent years, international student activism has often taken the form of protests against growing tuition fees, student debt, and targeting various forms of discrimination and marginalisation (Nielsen 2019). In South Africa, student activism also relates closely to larger social struggles, including persistent socioeconomic inequalities, and perceived oppressive university systems that appear to marginalise and exclude some students (Stuurman 2018). 
The four quadrants in the model suggested by Dunne and Zanstra (2011) are a helpful way to organise different ways in which student voices are being used in higher education. The gradual move to increase students' involvement in institutional practices has led to the conceptualisation of students as partners, producers or change agents (Seale 2016). In turn, while the use of students' voices as evaluators of their educational experiences has become a popular method to measure institutional quality, some authors, such as Hall (2017 183) criticise the commercial value they have come to represent. She argues that the variety of student surveys has, to a degree, become a source of managerialistic rhetoric, and has "diluted" the potential contribution of such voices to informing educational experiences. "Our greatest challenge now is how to facilitate the creation of spaces in which student voice is not merely demonstrated as being present, but in which that presence also has power, authenticity, and validity" (Hall 2017, 183). Flowing from this concern, we aim to illustrate how students' voices are contributing to our design of institutional practices that enhance quality and success for students.

\section{USING STUDENT VOICE TO GUIDE INSTITUTIONAL DESIGN}

Using the University of the Free State (UFS) as a case example, we draw from different data sources to illustrate how a variety of student voices are influencing institutional design, and in turn, how the intentional design of practices is promoting quality outcomes and students' success. This reiterative process embodies principles of action research in that it aims to improve educational practice, implement actions, incorporate research, critical reflection of actions and outcomes, and in turn, these factors inform the next actions (Costello 2003).

Between 2009 and 2012 the UFS contextualised and piloted the South African Survey of Student Engagement (SASSE) and has been administering the survey on a national basis ever since. The UFS' commitment to student engagement and creating an evidence-based culture to inform decisions led to the strategic positioning of four high-impact practices within the Centre for Teaching and Learning (CTL). These include Academic Advising, the Academic Student Excellence Tutorial Programme (A_STEP), the UFS101 first-year experience, and the Unit for Language Development's academic literacy course (see Table 1). In essence, high-impact practices are scaled interventions requiring intentional investment of time and resources, and have been proven to optimise students' development. These practices can take place within or beyond classrooms and have a specific focus on cultivating interactions between students, diverse peers, as well as with staff members. Through these interactions, students also receive feedback on their progress and development (Kuh 2008). To illustrate how student voice is used to inform these practices, we focus on the A_STEP tutorial programme and Academic Advising. 
Table 1: High-impact practice participation, 2019

\begin{tabular}{|l|c|}
\hline \multicolumn{1}{|c|}{ High-impact practice } & $\begin{array}{c}\text { Number of students } \\
\text { participating }\end{array}$ \\
\hline UFS101 & 8,500 \\
\hline A-STEP & 13,300 \\
\hline Academic Advising (Face-to-face, group advising and digital platforms) & 12,981 \\
\hline Language development: compulsory courses & 10,501 \\
Students making use of academic writing support & 15,568 \\
\hline
\end{tabular}

\section{THE A STEP TUTORIAL PROGRAMME}

The A_STEP programme started in 2007 with 55 tutors providing support for two faculties. Since then, the programme has been positioned as a high-impact practice and has grown to 312 tutors providing support in seven faculties across two campuses at the UFS. The programme takes on a hybrid form, drawing from supplemental instruction and tutorial principles. Tutors are also provided with training in classroom and peer facilitation. The A_STEP programme makes use of the following data sources from students to inform practice: student and tutor evaluations, SASSE surveys, student behavioural data (data analytics), and other research and analyses.

Student and tutor evaluations are administered once a semester and focus on students' and tutors' experiences in respective modules. From the students' side, this includes feedback on the relevance of the tutorials to their studies, the benefits or value they got from these interactions, an evaluation of the class environment and interactions with the tutors, as well as their feedback on the quality of learning facilitation.

The SASSE data provides an institutional perspective of students who take part in peer learning. It also allows for deeper analyses when combined with institutional data. Aligned with the literature on the value of peer learning as contributor towards students' success shared earlier, students who attend tutorials are more engaged learners; the more students attend tutorials, the better they perform academically; and it is the students with relatively lower Admission Point scores who attend tutorials more frequently. Additional findings that support peer learning as a high-impact practice include that students who participate in peer learning have better relationships with students and staff; students who participate in peer learning develop a wider variety of graduate attributes during their time in higher education; students who participate in peer learning also take part more in other high-impact practices, such as academic advising; and acting as a peer facilitator, tutor or mentor contributes significantly to the development of valuable graduate attributes (CTL 2019).

The scale of A-STEP requires sophisticated data analytics to manage the programme. Such analytics allow tracking student attendance and generating automated reports for faculties. The 
A_STEP programme has also started to engage with learning analytics on an individual student level through nudging campaigns, which seems to be a promising avenue to reach students who might need additional support. Lastly, additional research with students allows the incorporation of students' voices into tutorial practices. For example, a recent Journey Mapping qualitative project within CTL asked 160 students to identify factors that help them succeed. Tutorials stood out as one such factor that helps first-year students transition and adapt to university life, as well as facilitating their learning processes, and equipping them with academic confidence. Some examples of students' experiences include:

"A-STEP is very helpful because you get to a class, and there's a lot of students - in such a way that you cannot even express in words. So, A-STEP helped me because I'm in a smaller group and everyone gets to talk one by one up until you get used to it." (First-year student).

"Tutoring is essential, especially for first years, when they're trying to get used to the environment. I think it's really important and it's an advantage having tutors because they're more like the link between the lecturers and the students." (First-year student).

"Tutorials in different languages is a brilliant concept. It helped all of us." (Senior undergraduate student).

"In our tutorial sessions, we learned more than in the actual lecture itself." (Senior undergraduate student).

Students who have acted as tutors in the A_STEP programme also commented on the programme's influence on their development:

"When you become a tutor, you realise then that your knowledge is not as strong as you thought it was and you go polish that a bit. You get certain skills like speaking in front of an audience, structuring your timetables, managing your time etc. which of course prepares you for working." (Senior undergraduate student).

Some students also noted the importance of having good tutors, as well as environments conducive to discussions.

"Some tutors function better than others, like for example now I have a tutor who doesn't know half the content that she's tutoring. So, in essence we go to class confused, you're even more confused." (Senior undergraduate student).

"Tutorials sessions as well as practicals. The purpose of it is for discussions but the problem is that the venues are not conducive for discussion." (Senior undergraduate student).

\section{ACADEMIC ADVISING AS HIGH-IMPACT PRACTICE}

The UFS has been playing a leading role in developing academic advising in the South 
African context. Similarly, within the UFS context, academic advising has been positioned as a high-impact practice in order to reach more students and align practices between faculties and support structures. Incorporating students' voices through surveys and other research practices, as well as through data analytics, allows academic advising to address students' needs at scale, as well as individually.

In 2018, the CTL released a report making the link between academic advising, student engagement and students' academic success. Students who take part in academic advising are more engaged, and have a higher probability of passing more of their modules than comparable student groups (CTL 2018). The SASSE data also shows how positioning academic advising as a high-impact practice is creating more awareness among students. Figure 2 shows that more students engaged in advising in 2019 than in 2015 .

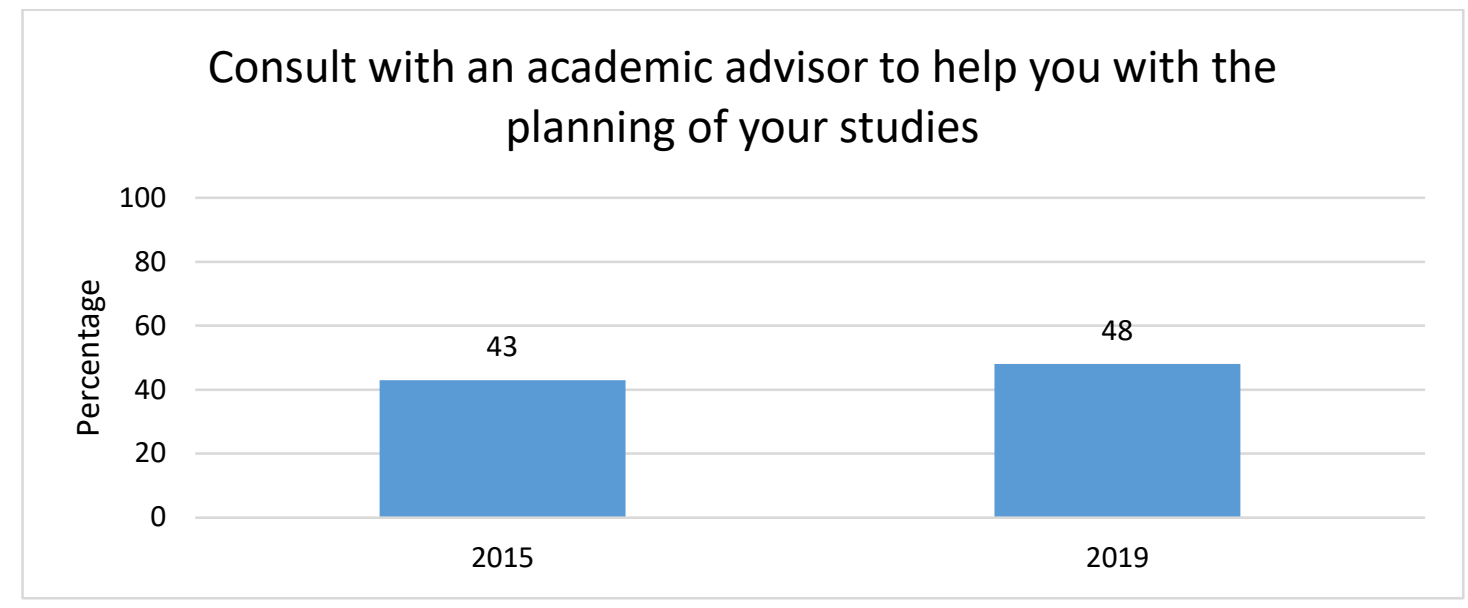

Figure 2: UFS students' participation in academic advising

Other research, such as the Journey Mapping project introduced earlier, helps advisors identify the role advising plays during different phases of students' educational journeys. For example, while the first two quotes below illustrate the value students experience when engaging with advising, the last three quotes show a need for advising to be available to students at an earlier stage to help them choose programmes, to be more proactive in equipping students with time management and other skills before it becomes a problem, and to incorporate career advising to align academic programmes with options after they graduate.

"It should be compulsory for every student to get academic advising before they register for a degree and academic advisors should have in-depth information on module combinations." (Senior undergraduate student).

"[Advising] is really, really helpful. I was having trouble with managing my study schedule and I 
had a problem with my modules and stuff, so I got proper advice regarding the course that I'm doing. I think it was information that I needed from the word go. It really helped to manage my time for the exams and to really do well." (First-year student).

"When I applied to study here, I didn't know anything about academic advising. I didn't know there was academic advising, I didn't know, and I just thought like, you choose something that you want to study and that's it." (First-year student).

"You only get assistance with study methods and study times and notional hours when you already have a problem." (Senior undergraduate student).

"I just wish like, it could be more career driven." (Senior undergraduate student).

Lastly, incorporating data analytics into a case management system developed for the academic advising team allows advisors to track the reasons for student visits, as well as the peak of advising sessions. This, in turn, informs the content of digital advising magazines, as well as developing more proactive interventions to address student needs.

\section{CONCLUSION}

Students' voices are being incorporated in various ways in the daily functioning of higher education institutions. This takes place through a variety of roles, where students contribute their experiences, thoughts and knowledge as representatives of the broader student population. All methods of inclusion and voice contribute to enhancing the quality of education, whether they have an impact on pedagogy, governance, awareness through activism, or contribute to institutional interventions. Yet, large-scale evidence of the impact of student voices on higher education is hard to find.

This article attempted to show that, regardless of the method of inclusion of student voice - whether it is through surveys or empowering students to be change agents - it is how those voices are used to impact the quality of the educational experience that matters. Turning back to Dunne and Zunstra's model (2011), it is important that a variety of student voices are represented in all four quadrants. It is also important that a variety of student voices are represented within each of the quadrants. As illustrated by the high-impact practices at the UFS, a variety of student voices shape how these large-scale interventions support and develop students. Different channels to engage with students also allow more student voices to be heard. In addition to student voice, scaled practices also require data analytics to help us understand the behaviours of our students and how we can leverage technology to create individualised support for them.

Investing in high-impact practices that are continuously informed by students' voices could contribute significantly to the complexity of quality outcomes. In addition, such practices have the potential to make an impact on persistent inequities in the system, as their 
developmental impact cuts across the spectrum of student groups. A focus on building a body of evidence from these institutional initiatives could bring to light the intentional and unintentional attributes developed through these practices that could also contribute to a more concrete understanding of the capabilities with which graduates leave institutions. Diversity in students' voices should therefore form an essential part of institutional initiatives to improve student success, quality and teaching and learning.

\section{NOTES}

1. A review of annual CHE Vital Stats publications from 2010 to 2017.

2. http://nsse.indiana.edu/html/how_institutions_use_NSSE.cfm

\section{REFERENCES}

Barnett, R. 1994. Power, enlightenment and quality evaluation. European Journal of Education 29(2): $165-179$.

Brooman, S., S. Darwent and A. Pimor. 2015. The student voice in higher education curriculum design: Is there value in listening? Innovations in Education and Teaching International 52(6): 663-674.

Canning, J. 2017. Conceptualising student voice in UK higher education: four theoretical lenses. Teaching in Higher Education 22(5): 519-531.

Centre for Teaching and Learning. 2018. Creating pathways for student success: Academic advising and student engagement. UFS: CTL.

Centre for Teaching and Learning. 2019. Creating pathways for student success: Peer learning, engagement and success. UFS: CTL.

CHE see Council on Higher Education.

Cloete, N. 2016. Free higher education: Another self-destructive South African policy. Centre for Higher Education Trust. https://www.chet.org.za/files/Higher\%20education\%20and\%20Self\%20 destructive\%20policies\%2030\%20Jan\%2016.pdf (Accessed January 2020).

Costello, P. J. M. 2003. Action research. London: Continuum.

Council on Higher Education. 2014. Framework for institutional quality enhancement in the second period of quality assurance. Pretoria: CHE.

Council on Higher Education. 2015. Content analysis of the baseline institutional submissions for phase 1 of the Quality Enhancement Project. Pretoria: CHE.

CTL see Centre for Teaching and Learning.

Department of Higher Education and Training. 2018. A National Framework for Enhancing Academics as University Teachers. Pretoria: DHET.

Department of Higher Education and Training. 2019a. Statistics on Post-School Education and Training in South Africa 2017. Pretoria: DHET.

Department of Higher Education and Training. 2019b. 2000 to 2016 First time entering undergraduate cohort studies for public higher education institutions. Pretoria: DHET.

Dos Reis, K. M. and D. Yu. 2018. Peer mentoring: Enhancing economics first years' academic performance. South African Journal of Higher Education 32(6): 234-250.

Dunne, E. and R. Zandstra. 2011. Students as change agents: New ways of engaging with learning and teaching in higher education. Bristol, UK: University of Bristol, ESCalate.

Fomunyam, K. G. 2016. Theorising student constructions of quality education in a South African 
university. Southern African Review of Education 22: 46-63.

Hall, V. 2017. A tale of two narratives: Student voice - what lies before us? Oxford Review of Education 43(2): 180-193.

Hazelkorn, E., H. Coates and A. C. McCormick. 2018. Research handbook on quality, performance and accountability in higher education. Northampton. MA: Edward Elgar Publishing.

Klemenčič, M. and I. Chirikov. 2015. "How do we know how students experience higher education? On the use of student surveys." In The European higher education area: Between critical reflections and future policies, ed. A. Curaj, L. Matei, R. Pricopie, J. Salmi and P. Scott. London: Springer.

Knoesen, R. and L. Naude. 2017. Experiences of flourishing and languishing during the first year at university. Journal of Mental Health 27(3): 269-278.

Kuh, G. D. 2008. High-impact educational practices: What they are, who has access to them, and why they matter. Washington, DC: Association of American Colleges and Universities.

Layton, D. M. 2015. The role of the tutorial system in enabling students' academic success. South African Journal of Higher Education 29(4): 198-210.

Makala, Q. 2017. Peer-assisted learning programme: Supporting students in high-risk subjects at the Mechanical Engineering Department at Walter Sisulu University. Journal of Student Affairs in Africa 5(2): 17-31.

Manik, S. 2015. As a person you need help every now and then: Accessing students' support needs in a higher education environment. South African Journal of Higher Education 29(3): 101-117.

Masehela, L. M. and M. Mabika. 2017. An assessment of the impact of the Mentoring Programme on student performance. Journal of Student Affairs in Africa 5(2): 163-182.

Mayet, R. 2016. Supporting at-risk learners at a comprehensive university in South Africa. Journal of Student Affairs in Africa 4(2): 1-12.

McGhie, V. and M. du Preez. 2015. Addressing the learning needs of at-risk students at the University of the Western Cape. South African Journal of Higher Education 29(1): 164-180.

McKay, T. M. 2016. Do tutors matter? Assessing the impact of tutors on first-year academic performance at a South African university. Journal of Student Affairs in Africa 4(1): 53-64.

Mudehwe-Gonhovi, F. R., G. Galloway, and G. Moyo. 2018. Dialogic pedagogical innovation: Creating liberating learning practices for first year university students. South African Journal of Higher Education 32(5): 140-157.

Ndebele, T. 2017. "Education.” In South Africa Survey 2017, ed. F. Cronje and T. Ndebele. South African Institute of Race Relations: Johannesburg.

Nel, L. 2017. Students as collaborators in creating meaningful learning experiences in technologyenhanced classrooms: An engaged scholarship approach. British Journal of Educational Technology 48(5): 1131-1142.

Nielsen, G. B. 2019. Radically democratising education? New student movements, equality and engagement in common, yet plural, worlds. Research in Education 103(1): 85-100.

OECD see Organisation for Economic Co-operation and Development.

Organisation for Economic Co-operation and Development. 2017. Getting skills right: Skills for jobs indicators. OECD Publishing.

Reddy, V., M. Rogan, B. Mncwango and S. Chabane. 2017. Occupations in high demand in South Africa: A Technical Report. Pretoria: Labour Market Intelligence Partnership.

Republic of South Africa. 1997. Higher Education Act of 1997. https://www.gov.za/documents/highereducation-act (Accessed January 2020).

Seale, J. 2016. How can we confidently judge the extent to which student voice in higher education has been genuinely amplified? A proposal for a new evaluation framework. Research Papers in Education 31(2): 212-233. 
Shah, M., M. Cheng and R. Fitzgerald. 2017. Closing the loop on student feedback: The case of Australian and Scottish universities. Higher Education 74: 115-129.

Statistics South Africa. 2019. Youth graduate unemployment rate increases in Q1: 2019. http://www.statssa.gov.za/?p=12121 (Accessed March 2020).

Stuurman, S. 2018. Student activism in a time of crisis in South Africa: The quest for "black power". South African Journal of Education 38(4). DOI: 10.15700/saje.v38n4a1704.

Waghid, Y. 2019. Quality, dissonance and rhythm within higher education. South African Journal of Higher Education 33(3): 107. 